\title{
PER CAMINS INUSSITATS I SENDES MOLT APARTADES. CONTRABANDO DE SEDA VALENCIANA HACIA CASTILLA DURANTE LA SEGUNDA MITAD DEL SIGLO XVI
}

\author{
DANiel MuÑoz NaVARro* \\ Scuola Superiore di Studi Storici. Università degli Studi di San Marino \\ Departament d'Història Moderna. Universitat de València
}

Fecha de recepción: enero 2015

Fecha de aceptación: mayo 2015

En los últimos años, los estudios sobre fronteras han vivido una importante reactivación, especialmente de la mano de la historia comparada y de la transnacional ${ }^{1}$. A tenor de las aportaciones más recientes y de las fuentes documentales, resulta evidente que las fronteras históricas no eran elementos fosilizados ni barreras infranqueables, sino más bien elementos dinámicos y permeables (moldeados por la coyuntura), que trataban de regular los contactos (fundamentalmente de tipo comercial) entre dos entidades políticas, fiscales y administrativas diferenciadas, aunque obligadas a entenderse.

Fruto de esta permeabilidad y del limitado control que las autoridades podían ejercer en estas zonas de tránsito fue la relevancia adquirida por la criminalidad fronteriza, en sus diferentes vertientes (contrabando, bandolerismos, asaltos...), durante

\footnotetext{
* Investigación desarrollada en el marco del proyecto «Nuevas perspectivas de historia social en los territorios hispánicos del Mediterráneo Occidental en la Edad Moderna» (HAR2014-53298-C2-1), financiado por el Ministerio de Economía y Competitividad. Así mismo, el autor también ha contado con el apoyo institucional de la Scuola Superiore di Studi Storici de la Università degli Studi di San Marino, como investigador postdoctoral de la misma.

1. Dos recientes estudios que abordan la cuestión con un enfoque internacional, que abarca el ámbito mediterráneo: Melón JimÉnEZ, Miguel Ángel, Rodríguez CANCHo, Miguel, Testón NuÑEz, Isabel y SÁNCHeZ Rubio, Rocío (eds.): Fronteras e historia. Balance y perspectivas de futuro, Gehsomp. Badajoz, 2014. Guia Marín, Lluis, Mele, Maria Grazia y Tore, Gianfranco (eds.): Identità e frontiere. Politica, economia e società nel Mediterraneo (secc. XIV-XVIII), Franco Angeli, Milán, 2014.
} 
toda la Edad Moderna². Los estudios de Miguel Ángel Melón Jiménez han analizado esta realidad en Extremadura y Portugal en los siglos modernos, y sin duda representan un referente en este tipo de investigaciones ${ }^{3}$. Pero el contrabando no fue exclusivo de las fronteras entre dos reinos, sino que también estuvo muy presente en las aduanas interiores de la Monarquía Hispánica, tales como la extensa frontera terrestre entre el Reino de Valencia y la Corona de Castilla. No por casualidad, James Casey hace referencia a esta línea divisoria, afirmando que a finales del siglo XVI el problema más serio allí era la epidemia de contrabando de seda en bruto a través de las aduanas fronterizas con Castilla, relacionando este hecho con dos aspectos clave: la falta de respeto a la ley y el recurso frecuente del uso de la violencia ${ }^{4}$.

La proliferación del comercio ilícito respondía normalmente a un patrón común: la existencia de una actividad económica dinámica, las dificultades de suministro de alguna mercancía o materia prima, y, por último, la imposición de tributos (ordinarios o extraordinarios) sobre la misma, que propiciaban la búsqueda de vías alternativas. Todos estos factores confluían en la Valencia del Quinientos, donde el contrabando de seda valenciana hacia Castilla se generalizó desde mediados de siglo, llegando a convertirse en un modo de vida en las principales regiones productoras (especialmente la Ribera del Júcar) y un motivo constante de litigio para las autoridades, incapaces de frenar este tráfico ilícito ante la insuficiencia de medios y la colaboración popular recibida. A través de este estudio analizaremos este tráfico fraudulento entre Valencia y Castilla, que ponía de manifiesto el débil control que existía en las fronteras entre ambos reinos y la ineficacia de las medidas punitivas y judiciales frente a las artimañas de los productores sederos, la connivencia de las autoridades y arrieros castellanos, y la intermediación de los mercaderes toledanos, principales agentes de este contrabando.

\section{LOS FACTORES CLAVE EN EL DESARROLLO DEL FRAUDE DE SEDA HACIA CASTILLA DURANTE LA SEGUNDA MITAD DEL SIGLO XVI}

Seda per pa: dit cruament, aqueixa era la estratègia del comerç valencià en temps dels Habsburgo. De esta manera tan tajante definía James Casey la importancia del comercio de intercambio de seda valenciana por trigo castellano a lo largo de los siglos

2. Al respecto, véase CATALÁ, Jorge y UrzaInQui, Sergio: «Nemo teneatur ad impossible. Las consecuencias de la pragmática para la extirpación del bandolerismo valenciano: cláusulas relativas a la punición de homicidios (1586-1604)», Revista de Historia Moderna. Anales de la Universidad de Alicante, 32 (2014), pp. 147-179.

3. Los trabajos de Miguel Ángel Melón sitúan la frontera como objeto historiográfico central de sus investigaciones: Hacienda, comercio y contrabando en la frontera de Portugal (siglos XV-XVIII), Cicon, Badajoz, 1999; Los tentáculos de la hidra. Contrabando y militarización del orden público en España (1784-1800), Sílex, Madrid, 2009. Referido al contexto europeo, véase Alloza Aparicio, Ángel: Europa en el mercado español. Mercaderes, represalias y contrabando en el siglo XVII, Junta de Castilla-La Mancha, Salamanca, 2006.

4. CASEY, James: España en la Edad Moderna: Una historia social, Madrid, 2001, p. 269. 
XVI y XVII. Se comprende, por tanto, el interés de las autoridades por fiscalizar este comercio, que, por lo que se refiere a la seda, se realizaba en buena medida a través de contrabando ${ }^{5}$. No por casualidad, durante la segunda mitad del XVI, la ciudad de Toledo se convirtió en el principal centro sedero de la Monarquía Hispánica, tras la decadencia de la sedería granadina ${ }^{6}$. Este hecho hizo que se convirtiese en un foco de atracción para la materia prima de seda que se producía en España, ante la necesidad imperiosa de cubrir la demanda del gran número de telares existentes en esta ciudad castellana. Las principales regiones sericícolas se situaban en el levante español, concretamente, los reinos de Murcia y Valencia, lo que produjo un flujo comercial constante entre estas regiones y el interior peninsular ${ }^{7}$. No obstante, en el caso valenciano, este comercio topaba con un problema añadido: la aduana y puerto seco $\mathrm{y}$, en consecuencia, la política fiscal.

El desarrollo de una incipiente sericicultura en el territorio valenciano se remontaba al siglo XV, aunque el periodo de mayor expansión se alcanzó durante la segunda mitad del Quinientos. Las autoridades valencianas comenzaron a centrar sus pretensiones fiscales en el comercio exportador de esta materia prima, ante las crecientes necesidades pecuniarias que suponía la defensa de la costa. El surgimiento de un impuesto específico que gravaba el comercio de seda con Castilla supuso un importante hándicap para los familias campesinas valencianas dedicadas a esta actividad agroindustrial, promoviendo el desarrollo de mecanismos (lícitos e ilícitos) para eludir el pago de la tasa, como veremos más adelante.

Desde la perspectiva valenciana tradicionalmente se ha señalado que la represión posterior a las Germanías afectó muy negativamente a la industria sedera valenciana, poniendo el acento en cómo esta crisis favoreció la corriente comercial de seda (hilada o torcida) hacia Toledo. No obstante, en los últimos años, esta visión ha sido matizada, a favor de una explicación más compleja. Sin negar que el Reino de Valencia acabó convirtiéndose en un territorio especializado en la producción de materia prima destinada a la exportación ${ }^{8}$, las transformaciones en la política fiscal y la evolución del gremi de velluters de Valencia apuntan a una crisis derivada del surgimiento de una tributación específica sobre el comercio de seda, debido a la pérdida de competitividad

5. CASEY, James: El regne de València al segle XVII, Afers, Valencia, 2006. (1. a ed. 1979), p. 106.

6. Montemayor, Julián: «La seda en Toledo en la Época Moderna», en VV.AA., España y Portugal en las rutas de la seda: diez siglos de producción y comercio entre oriente y Occidente, Universitat de Barcelona, Barcelona, 1996. Larruga ya hizo hincapié sobre esta industria. Véase: Memorias politicas y económicas sobre los frutos, comercio, fábricas y minas de España, Institución Fernando el Católico, Zaragoza, 1996 (ed. orig. 1789). Sobre Toledo, véase el Tomo V.

7. El desarrollo de la sericicultura valenciana y murciana coincide con la crisis de la granadina, más tradicional y muy gravada fiscalmente. FrANCH, Ricardo: «El comercio y los mercados de la seda en la España moderna», en Cavaciocchi, Simonetta (ed.), La seta in Europa. Sec. XIII-XX, Le Monier, Florencia, 1993, pp. 565-594. Una visión general sobre los principales centros sederos peninsulares en España $y$ Portugal en las rutas de la Seda, Universitat de Barcelona, Barcelona, 1996.

8. Sobre esta cuestión, véase FrANCH, Ricardo: «La evolución de la sedería valenciana en época de Felipe II» en Belenguer, Ernest (coord.), Felipe II y el Mediterráneo, SECC, Barcelona, 1999, pp. 289-310. 
que supuso para los tejidos valencianos, tanto en el ámbito internacional como en el mercado interior frente a los géneros de importación ${ }^{9}$. No obstante, coincidimos plenamente con Franch Benavent, ya que si las dificultades se incrementaron entonces, cabe suponer que previamente la manufactura habría conocido una etapa de expansión que contrarrestaría los efectos negativos producidos por las Germanías ${ }^{10}$.

La importancia adquirida por la producción de seda a mediados del Quinientos no pasó desapercibida para las autoridades valencianas, que vieron en esta materia prima una importante fuente de recursos fiscales, sin medir las consecuencias de sus políticas. Ante la acuciante situación financiera de la hacienda valenciana, en las Cortes de 1547 ya se indicaba que la cosecha de seda era la mayor del reino y se autorizaba a los representantes de los Estamentos a imponer los gravámenes necesarios para sufragar la defensa de la costa frente a los piratas norteafricanos y para garantizar el control de la población morisca. Sin embargo, fue en las Cortes de 1552 donde se procedió a crear una nueva imposición fiscal, el "nou imposit», desgajado del "general de la mercaderia», que gravaba, específicamente, el comercio de exportación de seda ${ }^{11}$.

La tasa sobre el comercio de seda se fijó inicialmente en el 5\% para la seda en bruto y en el 2,5\% para la torcida. No obstante, la tasa se incrementó en dos ocasiones más durante este periodo, debido a la escasa recaudación generada por este nuevo tributo, que nunca llegó a alcanzar las rentas previstas por las autoridades ${ }^{12}$. En 1564, pasaron a fijarse en el 7,08\% para la seda en madeja y el 4,58\% en la torcida; y en 1585 se volvió a incrementar el porcentaje, situándolo en el $12,50 \%$ y el 7,91\% respectivamente. A pesar de ello, estas medidas demostraron ser claramente ineficaces y contraproducentes para la economía valenciana. No únicamente no se alcanzó el objetivo para el que había sido creado (la financiación de la fortificación y defensa de la costa), sino que además esta política fiscal tuvo unas consecuencias inesperadas, lesionando los intereses de la manufactura sedera valenciana y contribuyendo a fomentar la exportación de la materia prima valenciana ${ }^{13}$.

A pesar de estos bruscos incrementos fiscales, la sericicultura valenciana continuó su proceso de expansión, convirtiéndose en una de las principales producciones del reino, incentivada por la demanda exterior y el comercio de exportación. Como consecuencia, buena parte de la producción sedera valenciana, localizada principalmente en las comarcas centrales del reino (La Ribera, La Costera, La Safor), se orientó

9. Estos planteamientos se ven apoyados por las tesis de R. Ling sobre exportación de tejidos valencianos hacia Castilla. LING, Richard: Long term in the trade of Valence, Alicante and the Western Mediterranean (1450-1700), Tesis Doctoral inédita, University of California, 1974.

10. Franch, Ricardo: «La evolución de la sedería...», op. cit., p. 295.

11. Castillo del CARpio, José María: «El sistema tributario del reino de Valencia durante el siglo XVI», Estudis, 19 (1993), pp. 103-130.

12. Ibid, p. 115.

13. Pardo Molero, Juan Francisco: La defensa del Imperio. Carlos V, Valencia y el Mediterráneo, Sociedad Estatal para la Conmemoración de los Centenarios de Felipe II y Carlos V, Madrid, 2001 y García MARTínez, Sebastián: Bandolers, corsaris i moriscos, Valencia, 1980. 
a la exportación de seda (en bruto o hilada principalmente) a Castilla, básicamente hacia Toledo, aunque también hacia Italia, a través del comercio marítimo internacional organizado desde el puerto de Alicante $^{14}$. Estas fueron las dos vías principales de extracción de la seda valenciana: una lícita, a través de la exportación de simiente de seda (ya que esta mercancía no pagaba el impuesto de la seda), y otra ilícita, por medio del contrabando de seda hacia Castilla, sobre la que centraremos nuestra atención en este trabajo.

Lo que resulta evidente es que la ineficacia del nuevo impuesto fue patente durante toda la segunda mitad del siglo XVI, de modo que este tributo tuvo que ser suprimido en las Cortes de 1604, debido al enorme comercio fraudulento que había generado, ya que, a pesar de la falta de estudios al respecto, la exportación ilegal debía de ser claramente superior a la controlada por los agentes fiscales ${ }^{15}$.

\section{EL CONTRABANDO DE SEDA Y SU REPERCUSIÓN SOBRE LA ECONOMÍA VALENCIANA}

Los factores mencionados anteriormente fueron los que motivaron el surgimiento de este intenso fraude físcal en la exportación de seda valenciana hacia Toledo. Este comercio estaba gravado doblemente, tanto por la fiscalidad foral (a través del nou imposit) como por la real (con los impuestos de peaje y quema que se cargaban en la exportación de productos hacia Castilla).

No en vano, sucesivas cridas reales y pragmáticas intentaron frenar los abusos cometidos en este comercio. A través de la legislación real se pretendía controlar este tráfico comercial, estableciendo la obligación de manifestar la producción de seda valenciana y su comercialización, con el objetivo de evitar estas prácticas fraudulentas. Pocos años después de la creación del nuevo impuesto, a la altura de 1558, fue publicada una crida real que obligaba a manifestar las compras de seda ante los representantes del rey antes de realizar cualquier compra-venta de seda. Pero la orden iba más allá, prohibiendo acoger o dar cobertura a los contrabandistas y señalando una de las maneras más habituales de extraer la seda sin pagar los tributos correspondientes: el uso de cuadrillas de hombres armados que custodiaban las cargas de seda hasta la frontera con Castilla ${ }^{16}$.

14. La exportación de simiente de seda hacia Italia es un tema prácticamente desconocido en la historiografía española, a diferencia de la italiana, que señala esta corriente exportadora como uno de los factores de desarrollo de la manufactura sedera lombarda y toscana durante el siglo XVI. Véase BATTISTINI, Francesco: L'industria della seta in Italia nell'età moderna, Bologna, il Mulino, 2003; MoIoli, Angelo: La gelsibachicoltura nelle campagne lombarde dal Seicento alla prima metà dell'Ottocento, Trento, Università degli Studi di Trento, 1981.

15. Franch, Ricardo: «La evolución de la sedería...», op. cit., p. 293.

16. Archivo del Reino de Valencia (ARV), Bailía letra P, sign. 316. Dentro de este proceso judicial se encuentra una trascripción de la crida real con fecha de 16 de Enero de 1558. «Que no gosse ni prexumesca fer contracte algú de compra de sedes sens que primer, ans de cloure dits contractes, done rahó [...] al tauleger dels drets de sa magestat del peatge y quema de la ciutat, vila o lloch hon faran dits contractes 
No obstante, a tenor del incremento de los procesos por fraude de seda en los años posteriores, parece que esta disposición tuvo escaso éxito, lo que obligó a reiterar la promulgación de este tipo de cridas durante toda la segunda mitad de la centuria (por ejemplo en 1581 y 1585), lo que es una muestra fehaciente del incumplimiento de la norma y de que no sólo no se redujo este contrabando, sino que éste incluso se intensificó durante este periodo ${ }^{17}$.

Pero, más allá de las disposiciones políticas, este contrabando se puede estudiar a través de los pleitos que se incoaban ante la Bailía General de Valencia, en representación de los intereses del Patrimonio Real, y ante los diputados de la Generalitat, por la denuncia de estos delitos. Dentro de esta documentación podemos encontrar, al menos, dos consultas elevadas al Baile General de Valencia por parte del procurador patrimonial del Rey y a instancia de los arrendadores de estos impuestos, denunciando el elevado porcentaje de fraude que se producía de manera cotidiana, el cual superaba ampliamente el volumen de seda que pagaba las contribuciones correspondientes. A través de estos documentos podemos reconstruir la naturaleza de este tráfico ilícito y tratar de aproximarnos al nivel de fraude que alcanzó el comercio de seda a Castilla.

R. Franch se hizo eco de la consulta planteada ante el Baile General de Valencia en 1580 por el notario Andreu Honorat Pineda, procurador patrimonial del Rey, en la cual argumentaba que, a pesar de la reiteración de las disposiciones contra el contrabando por parte de las autoridades, se seguían defraudando los impuestos correspondientes, remarcando el gran abús ques fa en lo present regne de traures de aquell la major part de la seda axi torçuda com de madexa per a Toledo, Sevilla e altres parts dels regnes de Castella e altres regnes. En esta consulta se denunciaba el hecho de que en determinadas regiones del reino, especialmente en la Ribera del Júcar, se había generalizado el fraude de seda, convirtiéndose en el medio de vida de buena parte de su población. No por casualidad, Pineda hacía referencia explícita a esta realidad social y a la impunidad con que se defraudaba en esta región, siendo sens comparació major lo abús ques fa de traure dita seda y los qui en fer fraus són mes culpats y mes ne abusen hi fan offici són los de L'Alcudia ${ }^{18}$.

Las fuentes documentales coinciden con lo expuesto por el procurador patrimonial, siendo frecuentes los pleitos por fraude de seda durante toda la segunda mitad del siglo XVI. A pesar de que se ha apuntado, en base al documento anterior, que la década de mayor fraude fue la de 1580, observamos un elevado número de pleitos por fraude

[...] e encara que no [...] gossen acompanyar ni fer acompanyar als portants y extraents les dites sedes en madeixa ni torçudes ni altres mercaderies ab arcabuços, scopetes, ballestes ni altre genero de armes, ni receptar, acollir ni hospitar aquells en llurs casses».

17. Una copia de la Real Crida de 1585 se encuentra en VALLÉs, Vicent: El conreu de la morera i l'artesania de la seda en la Ribera del Xúquer als segles XVI i XVII, Valencia, 1985, p. 70 y ss. Precisamente en esta crida se hace referencia a la promulgada algunos años antes, en 1581.

18. ARV, Generalitat, sign. 3319 (1580). Referencia extraída de FrAnCH, Ricardo: «La evolución de la sedería valenciana...», op. cit., p. 293. 
de seda prácticamente desde la creación del nuevo impuesto (1552) y especialmente a partir de los años sesenta ${ }^{19}$.

Precisamente, entre los fondos judiciales de la Bailía hemos podido localizar una consulta previa a la mencionada anteriormente. En 1572, Antonio Dixer, arrendador de los derechos del peaje y quema y buen conocedor de la producción y exportación de seda valenciana, elevaba una consulta al Baile General, en la que se cuantificaba el montante global del fraude de seda torcida hacia Castilla. El mencionado arrendador, refiriéndose exclusivamente a la ciudad de Valencia, decía que los más de noventa tornos existentes en ella estaban activos constantemente y su producción alcanzaba las 90.000 libras anuales de seda torcida, de les quals ne trauhen amagadament sens pagar los drets reals a sa magestat més de cinquanta millia lliures, perjudicando no sólo a las arcas públicas, sino también a los tejedores de seda concentrados en Valencia. La consecuencia principal del contrabando era el desabastecimiento local y el encarecimiento de la materia prima que estos utilizaban, la cual necesariamente debía de pagar los tributos establecidos ${ }^{20}$.

A pesar de que resulta difícil concretar unas cifras aproximadas de fraude en el comercio de seda, esta consulta nos aporta algunas indicaciones relevantes al respecto, afirmando que el contrabando de seda torcida en Valencia se situaba en torno al $55 \%$ (más de la mitad de la producción total). Pero, si esta era la realidad en la capital del reino, sin duda, este porcentaje se elevaba aún más en las áreas especializadas en la sericicultura, donde existían un número importante de tornos que no manifestaban su producción, ya que la mayor parte de la misma se comercializaba de manera fraudulenta hacia Castilla. De ahí que en el memorial de 1580 se apuntase un dato demoledor para las arcas reales, diciendo que cascun any nos cobra la quarta part del que s podría cobrar si nos fessen dits fraus, es decir, que en torno al 75\% de la seda exportada hacia Castilla defraudaba los derechos correspondientes ${ }^{21}$.

Aunque insistimos en que no existen datos contrastables para mesurar el volumen de fraude en este comercio, su relevancia era muy significativa y podemos afirmar con seguridad que la cantidad de seda exportada de manera ilícita era mayor que la que pagaba los tributos. Ambos memoriales coinciden en el menoscabo que este fraude provoca a la economía valenciana, ya que no sólo perjudicaba a las haciendas foral y real y a los arrendadores de derechos, sino que también producía una repercusión negativa sobre la industria de la seda de la ciudad de Valencia, debido a las dificultades generadas en el abastecimiento de materia prima.

Ambas consultas (la de 1572 y la de 1580) insisten en el daño generado por el contrabando de seda a la economía valenciana, aunque sin cuestionar la excesiva presión fiscal, causa profunda del crecimiento de este tráfico comercial fraudulento. Uno

19. ARV, Bailía Letra P, sign. 752. (1572). Que està en veritat que als dits drets reals de Sa Magestat e altres, de set o huyt anys a esta part poch mes o menys se han fet e fan mayors fraus que en molts anys atrás, trahent les dites sedes en madeixa, torçudes o teixides.

20. Ibid.

21. ARV, Generalitat, sign. 3319 (1580). 
de los factores en que coinciden ambos memoriales es la crisis de la industria sedera valenciana, ante la paralización que estaba generando el crecimiento del contrabando. En la consulta de 1572 se apuntaba la disminución de la población urbana, ante la crisis de las actividades productivas relacionadas con la seda. De modo que se han despoblat en la present ciutat prop de dos milia cases de velluters per no tenir fahena, per la necesitat e falta de seda [...] y per dita rahó de molts anys a esta part es anada la dita ciutat en disminució de població de persones que viuhen en lo exercici de dita seda» ${ }^{22}$.

Se denunciaba el flujo constante de seda valenciana, hilada o torcida, hacia diferentes centros industriales castellanos, fundamentalmente hacia Toledo, lo que afectaba a la competitividad de los tejidos valencianos, cuya materia prima sí satisfacía todas las tasas impuestas (con los ya mencionados incrementos fiscales del nou imposit). La generalización del contrabando hacia Castilla a través de la extensa frontera con Castilla, provocaba una situación paradójica, ya que, como se criticaba en ambas consultas, la seda valenciana se podía adquirir a mejor precio en Toledo que en Valencia ${ }^{23}$. De este modo, en la consulta de 1580 se declaraba que se poden donar los texits que:s fan en Castella molt més mercat que no los texits que porten a la present ciutat, com ab tot efecte se donen més mercat, siendo esta una de las causas principales de la decadencia de la industria sedera valenciana a finales del siglo XVI, ya que en Toledo, Sevilla, Cordova y Granada y altres parts de Castella van de cascun dia crexent los telers y los torns de seda y los velluters de la present ciutat y regne se van a viure a dites ciutats ${ }^{24}$

En definitiva, ambos memoriales coincidían en señalar al contrabando como uno de los enemigos principales de la manufactura sedera valenciana. Podemos afirmar que la política fiscal emprendida por las autoridades valencianas lastró a este sector económico, promoviendo, de manera indirecta, la búsqueda de vías alternativas (lícitas e ilícitas), a través de las cuales eludir el pago del tributo. En ninguno de estos memoriales se hace referencia a la represión posterior a la Germanía como causa de la decadencia de la sedería valenciana, lo que apoya la hipótesis de una recuperación posterior a la represión posterior a la Germanía, a pesar de la incidencia de ésta entre el grupo de sederos de Valencia. No obstante, este periodo de crecimiento se vería afectado por las excesivas cargas fiscales sobre la materia prima.

El fracaso de la política fiscal para la financiación de la defensa de la costa obligó a reconducir la situación a las autoridades valencianas. En las Cortes de 1604 se decidió suprimir el nou imposit de la seda, ante la escasa rentabilidad de este tributo y el auge del contrabando y la exportación de materia prima que había generado. No por casualidad, en este mismo parlamento se creó un impuesto específico sobre la exportación de simiente de seda, tratando de frenar este tráfico, que dificultaba enormemente

22. ARV, Bailía Letra P, sign. 752 (1572). A pesar de que probablemente se exageran las consecuencias, claramente se observa un conflicto de intereses entre los sericicultores y los sederos, el cual se mantuvo vivo durante toda la Edad Moderna.

23. Ibid. Se afirmaba que los que fraudulosament trauhen aquella que portant-la en Toledo la tenen més mercat que los officials que en Valencia la tixen.

24. ARV, Generalitat, sign. 3319 (1580). 
el abastecimiento de los telares valencianos y que apenas generaba ingresos fiscales. En definitiva, la política fiscal para la defensa del litoral valenciano durante la segunda mitad del siglo XVI fue siempre a remolque de la realidad comercial, obligando a reconducir esta situación a comienzos del siglo XVII, en las Cortes de $1604^{25}$.

\section{VÍAS DE EXTRACCIÓN Y PRÁCTICAS FRAUDULENTAS}

La documentación básica para este estudio son los procesos judiciales conservados en el Archivo del Reino de Valencia, concretamente en la sección de Bailía (letra P). Para el periodo que nos ocupa (segunda mitad del siglo XVI) encontramos un total de 1.169 procesos judiciales, de los cuales 143 hacen referencia exclusivamente al fraude de seda (12,23\% del total). A través de este fondo documental podemos conocer más detalladamente las vías de extracción de la seda y la naturaleza de estas prácticas fraudulentas.

Históricamente, el territorio valenciano ha estado muy vinculado con el interior peninsular, a través de constantes relaciones comerciales, políticas, humanas o culturales. Pese a la idea recurrente de la deficitaria red viaria de la España de Antiguo Régimen, diferentes estudios evidencian la conexión secular entre ambas regiones ${ }^{26}$. Las principales vías de comunicación entre el Reino de Valencia y Castilla fueron dos, el camino real por Almansa y el camino hacia Madrid a través de Requena ${ }^{27}$. Ambas ciudades eran las entradas naturales hacia la Corona de Castilla y allí se establecieron, por razones obvias, las aduanas y puertos secos correspondientes, con el objetivo de fiscalizar este tráfico constante.

Junto a estos dos pasos principales, la documentación judicial pone de manifiesto otra ruta importante en este contrabando, que se dirigía a través de la Canal de Navarrés, fundamentalmente por Enguera, en dirección a Ayora, hacia poblaciones castellanas como Casas de Ves o Carcelén desde donde las cargas de seda se remitían a Toledo. En cualquier caso, el volumen de fraude por esta vía, cuya orografía no favorecía especialmente el tránsito de mercancías, fue inferior respecto al de las otras dos rutas principales, mucho más accesibles y permeables ${ }^{28}$.

El contrabando de seda, al igual que el de cualquier tipo de mercancía, discurría a través de la red secundaria de caminos y sendas, con el fin de burlar la vigilancia aduanera, claramente insuficiente, a pesar de los esfuerzos de las autoridades por incremen-

25. Muñoz Altabert, Maria Lluïsa: Les Corts Valencianes de Felip III, Universitat de València, Valencia, 2005.

26. Muy ilustrativo en este sentido resulta el título de una obra de David Ringrose: Los transportes y el estancamiento económico de España (1750-1850), Tecnos, Madrid, 1972. Igualmente interesante, MADRAzo, Santos: El sistema de comunicaciones en España (1750-1850), Madrid, 1984 (2 vols.)

27. Muñoz Navarro, Daniel y Urzainqui Sánchez, Sergio: El Camino Real de Valencia a Castilla, S. $X V$-XVIII. El Camí de Requena, un itinerario histórico, Conselleria d'Infraestructures i Transport, Generalitat Valenciana, Valencia, 2011.

28. Son relevantes el número de pleitos relativos a fraude de seda por la zona de Ayora. Por ejemplo, ARV, Bailía P, sign. 561, 563, 565, 2425. 
tar la vigilancia de los caminos. Volviendo a la consulta de 1572, este documento hace referencia a este uso de vías secundarias por parte de los contrabandistas, los cuales tomaban la vía que discurría entre la ciudad de Valencia y la villa de Requena, de nit y en hora cauta per lo mur de fora de la ciutat, portant aquelles [las cargas de seda] com dit es en alqueries, camps y llochs de l'orta y contribució de aquelles y de allí per camins inussitats e sendes molt apartades de camins reals [...] portant aquelles ab dol e frau al Regne de Castella ${ }^{29}$.

A la altura de 1563, Francisco López de Úbeda, ciudadano de Toledo, fue acusado de defraudar dos cargas de seda que, según los testimonios, había comprado en Carlet, los cuales afirmaban que era vengut per hun camí que ninguna persona lo havia trobat e que no y havia molta difficultat ni menys fàcil cosa que traure seda furtant los drets en la ciutat e regne de Valencia ${ }^{30}$. A tenor de la documentación judicial, la facilidad con la que se extraía la seda del Reino de Valencia contribuyó, sin duda, a fortalecer este tráfico ilegal.

La seda, generalmente, viajaba a lomos de caballerías, no en carros, debido a la mayor lentitud de los mismos, a las deficiencias viarias y a la orografía del terreno, especialmente en las zonas escarpadas en la ruta de Xátiva (el puerto de Almansa), Requena (la sierra de las Cabrillas) y Ayora (la sierra de Enguera). Son frecuentes las referencias documentales en torno a las precauciones en el transporte de la seda, intentando ocultarla o disimularla, al menos hasta cruzar la línea divisoria de ambos reinos. Ante la multiplicidad de ejemplos que ilustran estas prácticas fraudulentas, hemos preferido elegir un caso que consideramos representativo. Nos referimos al pleito contra Paulo Casanova y Cristófol Montull, torcedores de seda valencianos, acusados de defraudar diferentes cargas de seda a través de la aduana de Requena. Se les inculpaba de sacar las cargas a lomos de sus caballerías, que baix portaven un albardo ab una manta ben sitgada y damunt hun sach de cherga negra a modo de salma plena de seda y ben sitgada y damunt venia hú dels sobredits y altres a cavall ab huns grans sperons y cada hú portava son pedrenyal y capuchos de cherga negra ${ }^{31}$.

Las quejas elevadas al Baile General y las disposiciones reales en contra del fraude de seda se hacían eco del uso frecuente de la violencia, a través de la formación de compañías de hombres armados que acompañaban las cargas de seda. Este hecho pone de manifiesto la magnitud de este flujo comercial y cómo esta actividad fraudulenta llegó a ser un auténtico modo de vida para algunas localidades, generalmente de la Ribera del Júcar (tales como L'Alcudia o Guadasuar), ya que buena parte de sus habitantes hacían del contrabando su actividad económica principal ${ }^{32}$. En estas consultas se

29. ARV, Bailía P, sign. 752 (1572).

30. ARV, Bailía P, sign. 439 (año 1564).

31. ARV, Bailía P, sign. 1098 (1593).

32. La importancia del fraude de seda para la economía local de algunas poblaciones de la Ribera se observa en la resistencia de algunas poblaciones (Xàtiva, Guadasuar, Alzira, L'Alcudia...) al control de su producción de seda por parte de los agentes reales en algunos pleitos. Véase los siguientes pleitos, ARV, Bailía P, Sign. 947, 1097, 1186, 2407. 
insiste en la indefensión de los guardas ante estas cuadrillas de hombres organizados y armados, ante la escasez de efectivos y medios para controlar la extensa frontera con Castilla.

En palabras de Hierony Audinet, credenciero de los derechos reales de su Magestad, los contrabandistas iban fuertemente armados, portant dits extrahents arcabussos, ballestes e altres armes ofensives, de tal manera que per cert ell és que ningunes guardes posades per a dits drets no són part ni poderosos per a remediar dits fraus. Así mismo, a fin de poder huir con facilidad en el caso de ser descubiertos por los guardas, los contrabandistas montaban siempre a caballo hasta cruzar la raya del reino, ab machos valents y no'ls carreguen sino mija carrega perque vajen lleugers perque cars quels encontren se puguen salvar com de fet se a vist diverses vegades ${ }^{33}$.

Estas cuadrillas solían contar con el apoyo y la connivencia de algunos naturales de las zonas por las que discurrían, especialmente de los hostaleros situados en los márgenes de los caminos a Castilla. Este es el caso de la cuadrilla de Joan Blanco, quien fue acusado de defraudar el derecho correspondiente de más de 3.000 libras de seda sacada fraudulentamente del reino por Almansa en 1550. Dentro del numeroso grupo de casi una veintena de personas reclamadas por la justicia, se incluye a vecinos de esta villa castellana, de Xátiva, Montesa, Alzira y Algemesí, además de Mateu Sancho, hostalero de Vallada, por su colaboración directa en el fraude o su apoyo a los mismos, acompanyat de moltes e diverses persones per aquell ajustades per al dit effecte de traure la dita seda armades de totes armes axi offensives com deffensives ${ }^{34}$.

A través de los testimonios de los pleitos podemos conocer, a grandes rasgos, cuáles fueron las principales técnicas y artimañas utilizadas por los contrabandistas para alcanzar la raya del reino. Unido al hecho de transitar por caminos secundarios o sendas poco transitadas y hacerse acompañar de hombres armados, como acabamos de mencionar, generalmente este tráfico se realizaba de noche y, en ocasiones, coincidiendo con días festivos, para evitar posibles eventualidades con los guardas.

Una vez alcanzada la frontera y cometido el fraude, el camino hacia Toledo se simplificaba y la seda solía transportarse a través de carruajes. En este punto, resultaba fundamental la colaboración entre productores valencianos, arrieros castellanos (generalmente de las poblaciones aduaneras de Almansa y Requena) y mercaderes de Toledo. En el caso anteriormente mencionado de Francisco López de Úbeda, la seda fue transportada hasta Toledo por Joan Carcajes, labrador de la villa de Requena, que había acordado transportar dos cargas de seda de 21 arrobas de seda a 3 reales y medio por arroba ${ }^{35}$.

A fin de ilustrar la colaboración entre los diferentes agentes sociales implicados en este comercio ilícito, recurrimos a uno de los pleitos de la Bailía: el proceso por fraude

33. ARV, Bailía P, sign. 752 (1572).

34. ARV, Bailía, P, exp. 2368 y 2369 (1551).

35. ARV, Bailía P, sign. 439 (año 1564). 
de seda contra Joan Marco y Bernat Cardona, labradores de L'Alcudia de Carlet ${ }^{36}$. Según la información proporcionada por los testimonios, éstos, junto a Juan Pérez, vecino de la villa de Requena staven en la ciutat de Toledo del Regne de Castella, en lo hostal vulgarment dit del Valencià, venent e o tenint venals públicament nou fardos de seda torçuda entre la qual y havia poch mes o menys de una arrova de seda en madeixa. Al parecer, la mencionada seda había sido extraída de manera fraudulenta del Reino de Valencia, llevándola hasta la villa de Requena a lomos de caballos, y de aquí a la ciudad de Toledo en carro. Esta segunda fase de transporte fue realizada por un vecino de Requena, del cual no se indica el nombre, lo qual era lo carreter que havia portat los dits nou fardos de seda ab lo seu carro de la vila de Requena fins la dita ciutat de Toledo y per que lo dit carro no se'n tornàs buyt de Toledo a la dita vila de Requena li trasaren certes càrregues de mercaderies ab que tornàs ${ }^{37}$. En este proceso se observa la doble participación de vecinos de Requena en este tráfico fraudulento de seda. En primer lugar, Juan Gómez, terciopelero de esta localidad, formaba sociedad con Joan Marco y Bernat Cardona para la comercialización de la seda. Por otra parte, el carretero encargado de transportar la mercancía hasta Toledo también era un castellano, que se beneficiaba de esta actividad fraudulenta.

Este pleito nos muestra un claro ejemplo de cómo las poblaciones fronterizas (como Almansa y Requena) jugaban un papel logístico clave en el contrabando de seda a Castilla, dando cobertura a los defraudadores e integrándose en las redes comerciales que conectaban la región productora valenciana y el mercado de la seda toledano. No por casualidad, una parte de la población de estas localidades castellanas participaba de las actividades económicas derivadas de este tráfico comercial ilícito, contribuyendo a su mantenimiento durante todo el periodo analizado.

\section{CONCLUSIONES}

La amplitud alcanzada por el contrabando en la frontera valenciana con Castilla durante la segunda mitad del siglo XVI nos obliga a plantear este estudio como una primera aproximación a la cuestión, que tendrá que ser ampliada con el análisis exhaustivo de la rica documentación judicial valenciana de la época. En él hemos tratado de aproximarnos al volumen de este tráfico fraudulento (que como hemos dicho superaba con creces al comercio lícito), los factores que lo promovieron, el contexto histórico en el que se inserta y las características generales del mismo. Las dificultades que presenta la cuantificación de este tráfico mercantil (tanto del legal como del fraudulento), debido a las carencias documentales y a la falta de estudios, pone en valor la importancia de estos pleitos que nos ofrecen una visión aproximada del alcance del contrabando de seda, tras la creación del nou imposit.

\footnotetext{
36. ARV, Bailía P, sign. 621 (1568). Sobre el fraude en la Ribera y el contrabando de seda como modus vivendi en La Ribera del Xúquer, remitimos al trabajo de Vicent Vallés Borràs, op. cit.

37. Ibid.
} 
La política fiscal para la defensa de la costa fracasó estrepitosamente. No sólo fue incapaz de alcanzar un nivel de recaudación suficiente para cubrir el elevado coste que ese objetivo requería, sino que, además de ello, incentivó el intenso fraude de seda entre Valencia y Castilla y, en paralelo, lastró la sedería valenciana durante esta centuria, ya que dificultó el abastecimiento de materia prima de los telares de la ciudad de Valencia. A consecuencia de ello y ante la ineficacia de este tributo, las autoridades políticas se vieron obligadas a decretar la supresión del nuevo impuesto en las Cortes de 1604, tratando de readaptar el sistema fiscal valenciano a la realidad social y comercial.

La falta de respeto a la ley primó entre buena parte de la población de las regiones sericícolas valencianas, que vieron en el contrabando un auténtico modo de vida, a pesar de las disposiciones políticas y de la acción judicial. La connivencia y el apoyo popular recibido por los contrabandistas en estas regiones nos permiten entender el gran auge de esta actividad en el periodo estudiado. Así mismo, la intensa demanda de los mercaderes toledanos y la colaboración de diferentes agentes sociales castellanos fomentaban este tráfico ilícito. Por último, cabe remarcar la impunidad manifiesta con que actuaban los contrabandistas, amparados en la escasez de medios para controlar un territorio de frontera como el Reino de Valencia, donde, a pesar de los esfuerzos de las autoridades, la criminalidad fronteriza (en sus diferentes formas) se mantuvo activa durante todo el Antiguo Régimen.

En cualquier caso, este estudio no puede abordarse únicamente desde una perspectiva local o regional, sino que hemos de situarlo en un contexto más amplio, que engloba diferentes regiones situadas en el ámbito del Mediterráneo Occidental. En definitiva, a través de nuestro estudio pretendemos realizar una primera contribución que se inserta en un debate de más amplio calado: el de la importancia del comercio terrestre, la relevancia de los contactos comerciales entre el Reino de Valencia y la Corona de Castilla y el desarrollo incipiente del mercado interior en la España del siglo XVI. 